\title{
Composition and element solubility of magnetic and non-magnetic fly ash fractions
}

\begin{abstract}
Magnetic and non-magnetic fractions of coal fly ashes from SE US electric power plants were characterized with special emphasis on the potential environmental consequences of their terrestrial disposal. Quartz and mullite were the crystalline minerals dominating the nonmagnetic fractions. Magnetic fractions contained magnetite, hematite, and, to a lesser extent, quartz and mullite. Chemical analyses revealed that magnetic fractions had about 10 times higher concentrations of $\mathrm{Fe}$, and $2 \mathrm{i} 4$ times higher concentrations of $\mathrm{Co}, \mathrm{Ni}$, and $\mathrm{Mn}$. Nonmagnetic fractions were enriched in $\mathrm{K}, \mathrm{Al}$ and $\mathrm{Ca}$. Iron content within fly ash particles was negatively correlated with elements associated with aluminosilicate matrix ( $\mathrm{Si}, \mathrm{Al}, \mathrm{K}, \mathrm{Na}$ ). Solubility of most elements was higher in the non-magnetic than in the magnetic fractions of alkaline fly ashes at comparable $\mathrm{pH}$. Calcium was associated with the non-magnetic fraction of the alkaline fly ashes which resulted in a higher $\mathrm{pH}$ buffering capacity of this fraction.
\end{abstract}

Keyword: Fly ash; Magnetic fraction; Non-magnetic fraction; Composition; Solubility 